\title{
Comparative Analysis of L-Carnitine Production by Y. Lipolytica in Different Conditions in Biofuel Waste and Fat-Acid Free Medium for Commercial Purposes
}

\author{
Monika Jach ( $\sim$ monijach@kul.pl ) \\ John Paul II Catholic University of Lublin \\ Konrad Kubiński \\ John Paul II Catholic University of Lublin \\ Ewa Sajnaga \\ John Paul II Catholic University of Lublin \\ Marek Juda \\ Medical University of Lublin \\ Anna Malm \\ Medical University of Lublin
}

\section{Research Article}

Keywords: biofuel waste, free-fat media, L-carnitine, oleaginous yeast, Yarrowia lipolytica

Posted Date: April 20th, 2021

DOI: https://doi.org/10.21203/rs.3.rs-423648/v1

License: (c) (1) This work is licensed under a Creative Commons Attribution 4.0 International License.

Read Full License 


\section{Abstract \\ Background}

Yarrowia lipolytica is an oleaginous yeast with the ability to grow in a variety of hydrophilic and hydrophobic substrates, including industrial wastes, in which it produces and accumulates various nutrients.

\section{Methods}

The aim of the present study was to examine the presence of free L-carnitine in the biomasses of two Yarrowia lipolytica strains (ATCC 9793 and A-101) growing in YPD medium and biofuel waste. The cultivations of $Y$. lipolytica were performed in aerobic conditions at different temperatures $\left(20-30^{\circ} \mathrm{C}\right)$ and $\mathrm{pH}$ values (4.0-7.0) of the media with and without the addition of precursors for L-carnitine production, such us iron, trimethyllysine, and L-ascorbic acid in a laboratory scale or chromium chloride (III) in a pilot plant scale.

\section{Results}

Both tested $Y$. lipolytica strains grown in fatty acid-poor YPD medium at $20^{\circ} \mathrm{C}$ and $\mathrm{pH} 6.0$ contained endogenous free L-carnitine in their biomass with a maximum of $22.85 \mathrm{mg} / 100 \mathrm{~g}$ of wet biomass. The addition of L-carnitine precursors to the YPD medium exerted a significant effect on L-carnitine concentration in the yeast biomass, increasing it up to $250 \%$. In turn, the biomass of both tested $Y$. lipolytica strains cultivated in the biofuel waste, irrespective of the culture conditions, contained below 1 $\mathrm{mg}$ of L-carnitine/100 $\mathrm{g}$ of wet biomass. However, the supplementation of the culture media with the Lcarnitine precursors significantly increased the yield of the yeast biomass by $20-30 \%$ in the biofuel waste cultures. Moreover, the addition of chromium(III) chloride into the biofuel waste caused an increase in the free L-carnitine concentration in the yeast biomass up to $2.24 \mathrm{mg} / 100 \mathrm{~g}$ of dry weight.

\section{Conclusion}

Biomass of $Y$. lipolytica grown in the free fat medium contained free L-carnitine, in contrast to the biomass grown in the fat-rich biofuel waste. The very low amounts of L-carnitine in the biomass of $Y$. lipolytica grown in the crude biofuel waste suggest that the yeast is able to utilize almost the entire pool of free L-carnitine for growth and nutritional biomass production. However, the addition of chromium to the biofuel waste contributed to an increase in L-carnitine concentration in Y. lipolytica biomass.

\section{Introduction}


L-carnitine or $\gamma$-trimethylamino- $\beta$-hydroxybutyric acid is a ubiquitous water-soluble quaternary amine compound $(1,2,3)$. It is synthesized by most eukaryotic organisms, including some yeast, from amino acids: Iysine as a precursor and methionine or S-adenosyl methionine as a methyl donor $(3,4)$. In humans, endogenous synthesis of L-carnitine occurs chiefly in the liver. However, it must be complemented through dietary uptake. Since it is regarded to be a quasi-nutrient or conditionally essential nutrient, Lcarnitine deficiencies sometimes cause life-threatening disorders. As an important factor in cellular metabolism, L-carnitine binds fatty acids and transfers them to the mitochondria for $\beta$-oxidation required for generation of energy. Without L-carnitine, the mitochondrial inner membrane is impermeable to fatty acids $(1,5,6)$.

The best-known yeast Saccharomyces cerevisiae is unable to synthesize L-carnitine. However, this yeast possesses enzymatic activities, especially carnitine acetyltransferases (CATs), which allow the uptake of $\mathrm{L}$-carnitine from the environment $(4,7,8)$. Studies reported elsewhere $(3,9,10,11)$ revealed that some oleaginous yeast, e.g. Candida albicans and Yarrowia lipolytica, synthesize de novo endogenous Lcarnitine. Similar to $S$. cerevisiae, $C$. albicans and Y. lipolytica have the activity of CATs; however, the oleaginous yeast is able to grow in a medium containing fatty acids without supplementary carnitine $(3,12)$. Additionally, Y. lipolytica possesses proteins for transport and activation of fatty acids (i.e. Faa1p, Pxa1p, Pxa2p, Ant1p) similar to those of $S$. cerevisiae. However, the activation and mechanism of the peroxisomal transport of fatty acids into $Y$. lipolytica mitochondria differ considerably from that in $S$. cerevisiae (12). In contrast to S. cerevisiae, Y. lipolytica has six additional acyl-coenzyme A (acetyl-CoA) oxidases (encoded by POX1-6 genes) with different chain-length specificities, which allow direct utilization of fatty acid-rich feedstock through complete oxidation using intermediates of $\beta$-oxidation $(9,13,14,15)$.

The availability of fatty acids from industrial by-products promotes the use of fatty acid-enriched feedstock as a cheap carbon source by oleaginous yeast (9). It has been shown that $Y$. lipolytica grown on a medium with different fatty wastes is a natural source of such nutritional components as single cell oils (especially mono-unsaturated fatty acids and saturated cocoa-butter equivalents), protein (i.e. single cell protein, SCP), amino acids, and B-group vitamins, including vitamin B12 $(16,17,18,19,20,21,22,24)$. In this respect, this yeast occupies an important place in pharmaceutical, feed, and food industry (20). Moreover, the use of this yeast biomass as an additional nutritional supplement can support a solution to the problem of food scarcity in the ever-growing human population, especially in developing countries such as India and Burkina Faso $(20,28)$. In 2019, the European Food and Safety Authority (EFSA) authorized the use of dried and heat-killed $Y$. lipolytica biomass as a novel food in dietary supplements intended for the general population above 3 years of age [29]. Furthermore, fatty waste biodegradation by this yeast is regarded as particularly relevant for environmental protection [24, 25, 26, 27]. Moreover, growing in nitrogen starvation conditions during lipogenesis, $Y$. lipolytica is also used for production of diesel-like fuels and oleochemicals from carbohydrate resources (31).

Previously, we reported that $Y$. lipolytica is able to produce protein, amino acids and generally an appropriate amount of vitamin B-enriched biomass when grown in biofuel waste $(18,19,32,23)$. However, 
there is hardly any information about the concentrations of free L-carnitine in $Y$. lipolytica biomass in literature. It is known that L-carnitine is required for fatty acid $\beta$-oxidation, which is the main pathway for fatty acid degradation in oleaginous yeast (9). Therefore, the aim of the present study was to assess whether biomass of $Y$. lipolytica cultivated in fat free YPD medium and fat-rich biofuel waste contained free L-carnitine.

\section{Results}

\section{Influence of culture conditions on the L-carnitine concentration in Y. lipolytica biomass}

The L-carnitine concentration in the yeast biomass was tested using both Y. lipolytica ATCC 9793 and Y. lipolytica A-101 strains growing in two culture media: standard fatty-free laboratory YPD and biofuel waste (SK medium). As shown in Fig. 1, free L-carnitine was detected in the biomass of Y. lipolytica cultured in the YPD medium in the different culture conditions. In the case of $Y$. lipolytica ATCC 9793, the maximum concentration of L-carnitine $(22.85 \mathrm{mg} / 100 \mathrm{~g}$ of wet biomass) was reached after 12-hour growth at the temperature of $20^{\circ} \mathrm{C}$ and $\mathrm{pH} 6.0$. This result was comparable to that obtained at the temperature of $30^{\circ} \mathrm{C}$ and $\mathrm{pH} 5.0$. The differences were not statistically significant $(P>0.05)$. On the contrary, in standard conditions $\left(30^{\circ} \mathrm{C}, \mathrm{pH} 6.0\right)$ in the YPD medium, the L-carnitine level produced by $Y$. lipolytica ATCC 9793 was 2 times lower $(9.93 \mathrm{mg} / 100 \mathrm{~g}$ of wet biomass) than that obtained at the temperature of $30^{\circ} \mathrm{C}$ and $\mathrm{pH} 5.0$. These differences were statistically significant $(P<0.01)$. The concentration of L-carnitine in the biomass of $Y$. lipolytica A-101 was statistically lower than in the $Y$. lipolytica ATCC 9793 biomass $(P<0.01)$ obtained in the same conditions (Fig. 1). Y. lipolytica A-101 growing in the YPD medium at the temperature of $30^{\circ} \mathrm{C}$ and $\mathrm{pH} 5.0$ produced a 2.5 times higher level of Lcarnitine $\left(7.09 \mathrm{mg} / 100 \mathrm{~g}\right.$ of wet biomass) than in the standard conditions $\left(30^{\circ} \mathrm{C}, \mathrm{pH} 6.0\right)$. These differences were statistically significant $(P<0.01)$.

\section{Influence of precursors on the L-carnitine concentration in Y. lipolytica biomass yields}

The addition of a low concentration of iron(II) sulfate $(0.001 \mathrm{~g} / \mathrm{L})$, trimethyllysine hydrochloride $(0.01$ $\mathrm{g} / \mathrm{L})$, and $\mathrm{L}$-ascorbic acid $(0.002 \mathrm{~g} / \mathrm{L})$ as precursors of $\mathrm{L}$-carnitine synthesis to the YPD medium $(3,4)$ did not influence the L-carnitine concentration in the Y. lipolytica ATCC 9793 biomass (Table 1). The differences in the L-carnitine concentration were not statistically significant in comparison to the Lcarnitine level in the biomass of the ATCC 9793 strain grown in the medium without these supplementations. However, a $25 \%$ increase in the L-carnitine content $(P<0.05)$ was reported in the biomass of the reference $Y$. lipolytica ATCC 9793 strain grown in the YPD medium supplemented with the higher concentration of iron(II) sulfate $(0.01 \mathrm{~g} / \mathrm{L})$ and trimethyllysine hydrochloride $(0.1 \mathrm{~g} / \mathrm{L})$ and the same concentration of L-ascorbic acid $(0.002 \mathrm{~g} / \mathrm{L})$. In the case of the $Y$. lipolytica A-101 strain, the addition of the low concentration of iron (II) sulfate $(0.001 \mathrm{~g} / \mathrm{L})$, trimethyllysine hydrochloride $(0.01 \mathrm{~g} / \mathrm{L})$, 
and L-ascorbic acid $(0.002 \mathrm{~g} / \mathrm{L})$ resulted in a $250 \%$ increase in the L-carnitine concentration in the yeast biomass in comparison to the A-101 strain cultivated in the medium without these additives (Table 1). These differences were statistically significant $(P<0.05)$. The further increase in the concentrations of iron (II) sulpfate $(0.01 \mathrm{~g} / \mathrm{L})$ and trimethyllysine hydrochloride $(0.1 \mathrm{~g} / \mathrm{L})$ in the YPD medium with $\mathrm{L}$-ascorbic acid $(0.002 \mathrm{~g} / \mathrm{L})$ caused no statistically significant change in the L-carnitine level in the yeast biomass in comparison with results obtained in the biomass of $Y$. lipolytica grown with lower amount of these compounds.

Table 1

L-carnitine concentration in the wet biomass of Yarrowia lipolytica cultured in YPD medium and biofuel waste.

\begin{tabular}{|c|c|c|c|c|}
\hline \multirow[t]{3}{*}{ medium } & \multicolumn{4}{|c|}{$\begin{array}{l}\text { L-carnitine concentration }(\mathrm{mg} / 100 \mathrm{~g} \text { wet } \\
\text { biomass) } \\
\text { Mean } \pm \text { Standard deviation (SD) }\end{array}$} \\
\hline & \multicolumn{2}{|c|}{$\begin{array}{l}\text { Y. lipolytica ATCC } \\
9793\end{array}$} & \multicolumn{2}{|c|}{ Y. lipolytica A-101 } \\
\hline & $\begin{array}{l}\text { YPD } \\
\text { medium }\end{array}$ & $\begin{array}{l}\text { Biofuel } \\
\text { waste }\end{array}$ & $\begin{array}{l}\text { YPD } \\
\text { medium }\end{array}$ & $\begin{array}{l}\text { Biofuel } \\
\text { waste }\end{array}$ \\
\hline unsupplemented & $\begin{array}{l}9.93 \pm \\
0.50\end{array}$ & $<1.00$ & $\begin{array}{l}2.80 \pm \\
0.05\end{array}$ & $<1.00$ \\
\hline $\begin{array}{l}\text { supplemented } \\
\text { iron(II) }(0.001 \mathrm{~g} / \mathrm{L}) \text {, trimethyllysine }(0.01 \mathrm{~g} / \mathrm{L}), \mathrm{L} \text { - } \\
\text { ascorbic acid }(0.002 \mathrm{~g} / \mathrm{L})\end{array}$ & $\begin{array}{l}10.99 \pm \\
0.55\end{array}$ & $<1.00$ & $\begin{array}{l}9.80 \pm \\
0.49 \star \star\end{array}$ & $<1.00$ \\
\hline $\begin{array}{l}\text { supplemented } \\
\text { iron(II) }(0.01 \mathrm{~g} / \mathrm{L}) \text {, trimethyllysine }(0.1 \mathrm{~g} / \mathrm{L}), \mathrm{L}- \\
\text { ascorbic acid }(0.002 \mathrm{~g} / \mathrm{L})\end{array}$ & $\begin{array}{l}12.41 \pm \\
0.62 * \star\end{array}$ & $<1.00$ & $\begin{array}{l}10.74 \pm \\
0.52 * \star\end{array}$ & $<1.00$ \\
\hline
\end{tabular}

We also tested the effect of the addition of the mixture of factors, i.e. iron(II) sulfate $(0.01 \mathrm{mg} / \mathrm{L})$, trimethyllysine hydrochloride $(0.1 \mathrm{~g} / \mathrm{L})$, and L-ascorbic acid $(0.002 \mathrm{~g} / \mathrm{L})$, to the SK medium (biofuel waste) on the yeast biomass yield (growth density, $\mathrm{OD}_{600}$ ), in comparison to the medium without these supplements (Fig. 2A, B). After 12-hour cultivation, the biomass yield of both yeast strains cultured in the SK medium without the additives was quite satisfactory $\left(\mathrm{OD}_{600} 1.5\right)$. However, the addition of these $\mathrm{L}-$ carnitine precursors caused a significant increase in the yield of both $Y$. lipolytica strains $(P<0.05)$. After 10-hour yeast cultivation, the addition of the mixture led to a $20 \%$ and $30 \%$ increase in the biomass yield of the reference Y. lipolytica ATCC 9793 strain and the A-101 strain, respectively. 
In this study, we also determined the content of free L-carnitine in the dried Y. lipolytica A-101 biomass (so-called Yarrowia powder) obtained through standard production of seven independent batches in a pilot plant scale in biofermentors. Five batches were cultivated -using unsupplemented biofuel waste (the SK medium). Another two batches were obtained using biofuel waste supplemented with chromium(III) chloride (100 mg/L). After drying, we obtained Yarrowia powder, which was amorphous hygroscopic beige-coloured powder with a slight yeast odor. L-carnitine was only detected in the dry biomass of $Y$. lipolytica cultured in the chromium-supplemented SK medium. In this case, the free L-carnitine concentration was comparable in both batches (mean $2.31 \mathrm{mg} \pm 0.13 / 100 \mathrm{~g}$ of dried biomass) (Table 2). However, the dry biomass of $Y$. lipolytica, grown in the chromium-unsupplemented biofuel waste contained below $1 \mathrm{mg}$ of L-carnitine/100 $\mathrm{g}$ of dry weight.

Table 2

Concentration of protein and free L-carnitine in the dried Yarrowia lipolytica A-101 biomass (Yarrowia powder) obtained after culturing in the SK medium (biofuel waste) in a pilot plant scale.

\begin{tabular}{|c|c|c|}
\hline Batch number ${ }^{1}$ & $\begin{array}{l}\text { Protein content } \\
\text { (\% of dry weight) }^{2}\end{array}$ & $\begin{array}{l}\text { Concentration of L-carnitine } \\
\text { (mg/100g of dry weight) } \\
\text { Mean } \pm \text { Standard deviation (SD) }\end{array}$ \\
\hline 1 (unsupplemented) & 49.3 & $<1.00$ \\
\hline 2 (supplemented $\mathrm{CrCl}_{3}$ ) & 41.9 & $2.37 \pm 0.13$ \\
\hline 3 (unsupplemented) & 42.6 & $<1.00$ \\
\hline 4 (unsupplemented) & 43.7 & $<1.00$ \\
\hline 5 (unsupplemented) & 44.8 & $<1.00$ \\
\hline 6 (supplemented $\mathrm{CrCl}_{3}$ ) & 42.0 & $2.24 \pm 0.11$ \\
\hline 7 (unsupplemented) & 41.9 & $<1.00$ \\
\hline Mean & 45.6 & 2.31 \\
\hline
\end{tabular}

\section{Discussion}

In the present study, we examined the effect of the culture conditions and two different media on the level of free L-carnitine in the biomass of $Y$. lipolytica strains. The results confirm other findings $(19,32,33,34,35)$ revealing that the fermentation process parameters can have a significant impact on improvement of the nutrient content in the biomass of the studied yeast strains. However, we showed that the concentration of free L-carnitine in the yeast biomass depended primarily on the medium used, and, to some extent, on the strains and culture conditions. The standard laboratory YPD medium does not 
contain fatty acids. Therefore, L-carnitine is not required to utilize the fat-free YPD medium by $Y$. lipolytica strains; hence, we detected endogenous free L-carnitine in this yeast biomass. The other medium used was biofuel waste with high contents of fatty acids. It is known that $Y$. lipolytica growing in fatty substrates is able to accumulate and store lipids $(15,34,36,37,38)$. Since extracellular carbon sources were depleted, the yeast utilized own storage lipids (body lipids) as a carbon and energy source, increasing the production of proteins $(16,17,39,40)$. Interestingly, a knockout of the sextuple $P O X$ genes in $Y$. lipolytica causes inability of this yeast to degrade storage lipids, leading to over-accumulation of fats in yeast cells $(12,15)$. Therefore, the biosynthesis of cellular proteins or polysaccharides and the fat-free biomass production are competitive to lipid accumulation $(39,40)$. We found previously that both $Y$. lipolytica strains (ATCC 9793 and A-101) utilized biofuel waste (the SK medium) to produce biomass with a high concentration of protein and amino acids, especially the A-101 strain $(18,32)$. In the present study of both $Y$. lipolytica strains grown in the biofuel waste at a temperature range from $20^{\circ} \mathrm{C}$ to $30^{\circ} \mathrm{C}$ and different $\mathrm{pH}$ values (from 4.0 to 7.0 ), we did not notice a significant influence in the L-carnitine concentrations. The level of L-carnitine was below $1 \mathrm{mg} / 100 \mathrm{~g}$ of wet biomass in all fermentation samples (data not shown). These results suggest that, irrespective of the culture conditions, both $Y$. lipolytica strains used the entire pool of endogenous free L-carnitine to utilize fatty acids from biofuel waste to grow and produce protein-enriched biomass. It is worth emphasizing that carnitine can also be used as a sole nitrogen source, most commonly through the glycine betaine pathway, where glycine conversion to serine is followed by deamination to form pyruvate and ammonia (1). It was proved that $Y$. lipolytica grown in biofuel waste was able to produce all amino acids $(18,32)$. However, it should be added that the reference $Y$. lipolytica ATCC 9793 strain did not grow at low pH (4.0 or 5.0) in the biofuel waste, in contrast to the growth in the YPD medium. In turn, the $Y$. lipolytica A-101 strain was able to grow at low pH (4.0 or 5.0$)$ in the biofuel waste.

Other studies (3) showed that another oleaginous yeast $C$. albicans strain, with deletion of all four genes determining the L-carnitine synthesis pathway, was unable to grow on fatty acids and to utilize either acetate or ethanol as carbon sources. In turn, a transfer of the gene encoding acetyl-CoA oxidase from $Y$. lipolytica to $S$. cerevisiae enabled $S$. cerevisiae to grow on fatty acid-rich feedstock (9). L-carnitine plays a very important role in the transport of long- to short-chain fatty acids out of the peroxisome, where $\beta$ oxidation is started, into the mitochondria, where the process is completed, by reversible esterification of the $\beta$-carbon hydroxyl group with a fatty acid to form 0 -acyl-carnitine. Cytosolic acyl-carnitine is then transported by CATs into the mitochondrial matrix with a simultaneous 1:1 exchange with intramitochondrial free L-carnitine located within the mitochondrial inner membrane (1). Interestingly, the supplementation with L-carnitine results in more effective fatty acids transport to the mitochondria, where their decomposition occurs in the $\beta$-oxidation process (42).

The possibility of biofuel waste utilization as a substrate by $Y$. lipolytica mainly depended on the strains and culture conditions. Our previous studies revealed that the temperature of $30^{\circ} \mathrm{C}$ and $\mathrm{pH} 5.0$ were more suitable for production of SPC, amino acids, and B-group vitamins by $Y$. lipolytica strains cultivated in both YPD and SK media (biofuel waste) than at pH 6.0 and the same temperature $(18,19,23,32]$. Noteworthy, the culture parameters (i.e. temperature and $\mathrm{pH}$ ) also strongly affect lipase activities. The 
maximum activity of lipases produced by $Y$. lipolytica is noted at a temperature between $30^{\circ} \mathrm{C}$ and $40^{\circ} \mathrm{C}$ and $\mathrm{pH} 5.0$ (41). Moreover, these culture conditions significantly influence $Y$. lipolytica lipid accumulation during the primary anabolic growth when cultivated on fatty substrates $(33,34,35)$.

After 12-hour cultivation, the $Y$. lipolytica A-101 strain entered the death phase, hence the noticeable decline in the number of living yeast cells (Fig. 2B). The results confirmed that the addition of precursors for L-carnitine production increased the growth and quantity of yeast biomass growing in the fat-acid-rich medium, i.e. biofuel waste. This confirms the previous reports that the growth of such oleoginous yeasts as $C$. albicans, $Y$. lipolytica, or engineered $S$. cerevisiae strains on nonfermentable fatty acid-rich carbon sources is possible only in the presence of L-carnitine biosynthesis intermediates $(3,6,9)$. In turn, in wild $S$. cerevisiae, peroxisomal membranes are impermeable to acetyl-CoA, which is produced in the peroxisome, when the yeast are grown on fatty acids as carbon source. Therefore, wild $S$. cerevisiae are not able to grow in fat-rich waste substrates (40. In this respect, production of nutritional yeast biomass by oleoginous species on available inexpensive wastes used as carbon and energy sources (e.g. biofuel waste) is desired by industry in the broad sense.

We also observed a stimulatory effect of chromium on the free L-carnitine production. Trivalent chromium, an essential trace element, was reported as a diet components improving glucose uptake and fat metabolism (43). Moreover, the deficiency of trivalent $\mathrm{Cr}$ may induce symptoms comparable to those associated with diabetes in mammals (44). Our experimental results showed that the introduction of water-soluble chromium ( $\mathrm{Cr}(\mathrm{III})$ ) salt as a component of biofuel waste as the culture medium for $Y$. lipolytica resulted in production of a slight amount of free L-carnitine by the yeast. This implies that $\mathrm{Cr}$ supported L-carnitine metabolism in some way in the yeast cells. Thus, it is likely that the amount of Lcarnitine in the yeast biomass would be affected by the addition of $\mathrm{Cr}$ to cultures. Hovewer, the issue of the chemical dependencies between $\mathrm{Cr}$ and L-carnitine in yeast cells needs further investigations.

Yarrowia lipolytica growing in fatty acid-enriched substrates, e.g. biofuel waste in aerobic environments probably uses the entire pool of endogenous L-carnitine for growth and production of biomass. Hence, crude biofuel waste, as an inexpensive substrate, can be utilized by $Y$. lipolytica for production of highvalue nutritional compounds but not free L-carnitine. The use of L-carnitine precursors contributes to production of greater amounts of L-carnitine on fat-free medium. Additionally, it can increase the yield of $Y$. lipolytica grown in both fatty acid-free medium and biofuel waste. Moreover, $Y$. lipolytica growing in fatfree media or substrates with a small amount of fatty acids, especially various bio-wastes, can be applied as an L-carnitine producer.

\section{Methods}

\section{Microbial Strains}

In the research, we used the wild-type yeast Yarrowia lipolytica A-101 strain obtained from Skotan S.A. (Poland) and the reference yeast Y. lipolytica ATCC 9793 strain obtained from LGC Standards. 
Production, harvesting of Y. lipolytica biomass, and yeast growth conditions

Y. lipolytica was cultured in two culture media: chemically defined YPD medium (Difco) and industrial SK medium as previously described (18). The SK medium is a waste from biofuel production. Biofuel is made through chemical reaction of vegetable oil with ethanol producing fatty acid esters (long-chain alkyl (methyl, ethyl, or propyl) esters). Crude biofuel waste consists of a mixture of vegetable oils with degumming and glycerol fractions (from $2-7 \% \mathrm{wt} / \mathrm{wt}$ ). The degumming fraction contains mainly phosphoric acid derivatives associated with fats and protein as well as free plant fats (up to $10 \%$ ), protein (up to $10 \%$ ), ash (up to $5 \%$ ). The SK medium as a biofuel waste also contains $\left(\mathrm{NH}_{4}\right)_{2} \mathrm{SO}_{4}(12.6 \mathrm{~g} / \mathrm{L})$, urea $(4.0 \mathrm{~g} / \mathrm{L}), \mathrm{MgSO}_{4}(1.0 \mathrm{~g} / \mathrm{L}), \mathrm{KH}_{2} \mathrm{PO}_{4}(0.5 \mathrm{~g} / \mathrm{L})$, and some amount of vitamins $\mathrm{B}$. The mean concentration of these vitamins in $100 \mathrm{ml}$ of the medium is as follows: $0.9 \mathrm{mg}$ of thiamine, $3.65 \mathrm{mg}$ of riboflavin, 3.38 $\mathrm{mg}$ of pyridoxine, $138 \mu \mathrm{g}$ of folic acid, and $6.2 \mu \mathrm{g}$ of cyanocobalamin. The SK medium was provided by Skotan S.A. (Poland). The biofuel waste, i.e. a partially refined, desalinated, and methanol-free by-product from biodiesel manufacture, was delivered by Lotos Group Refineries, Poland to Skotan S.A. Two experimental culture conditions were used during this study: 1) variable temperature (from $20^{\circ} \mathrm{C}$ to $30^{\circ} \mathrm{C}$ ) and constant $\mathrm{pH}(6.0)$ values; 2$)$ constant temperature $\left(30^{\circ} \mathrm{C}\right)$ and variable $\mathrm{pH}$ (from 4.0 to 7.0 ) values. The $\mathrm{pH}$ was adjusted to the required values by adding $1 \mathrm{M} \mathrm{NaOH}$ or $1 \mathrm{M} \mathrm{HCl}$, respectively. The sterile media in Erlenmeyer flasks $(150 \mathrm{ml})$ were supplemented with $\mathrm{FeSO}_{4}$, trimethyllysine hydrochloride, and Lascorbic acid. The following combinations were applied: a) iron(II) sulfate $(0.001 \mathrm{~g} / \mathrm{L})$, trimethyllysine hydrochloride $(0.01 \mathrm{~g} / \mathrm{L})$, and L-ascorbic acid $(0.002 \mathrm{~g} / \mathrm{L})$ with the final $\mathrm{pH} 6.0 ; \mathrm{b})$ iron(II) sulfate $(0.01$ $\mathrm{g} / \mathrm{L})$, trimethyllysine hydrochloride $(0.1 \mathrm{~g} / \mathrm{L})$, and L-ascorbic acid $(0.002 \mathrm{~g} / \mathrm{L})$ with the final $\mathrm{pH}$ 6.0. $Y$. lipolytica cultivated in the YPD broth at a temperature of $30^{\circ} \mathrm{C}$ and $\mathrm{pH} 6.0$ was the control culture. $Y$. lipolytica strains were cultured in Erlenmeyer flasks $(150 \mathrm{ml})$ and in a biofermentor $(100 \mathrm{~L})$ as a pilot plant scale as previously described $(18,23)$. The sterile SK medium in the biofermentor was prepared with and without chromium(III) chloride (10 mg/L). After 12-hours cultivation, the biomass from the biofermentor was transferred into a tumble dryer and dried at $165-175^{\circ} \mathrm{C}$ for 1 hour; this yielded dried biomass called Yarrowia powder.

Preparation of yeast disruption in bead mill

Yeast cells were disintegrated with the use of a bead mill (Minilys homogenizer, Bertin Technologies) with the power of $250 \mathrm{~V} \mathrm{AC} / 50-60 \mathrm{~Hz}$, and speed $5000 \mathrm{rpm}$. The total working volume of the mill tube was ca $2 \mathrm{ml}$. Zirconium-glass beads (Bertin Technologies) with diameter of $0.5 \mathrm{~cm}$ were used in the experiments. For a single homogenization, $50 \mathrm{mg}$ of the $Y$. lipolytica cells were used. The cells were resuspended in $0.5 \mathrm{ml}$ Tris- $\mathrm{HCl}$ buffer, $\mathrm{pH}$ 7.5. 3D beat-beating was carried out in cycles: $10 \times 1 \mathrm{~min}$. of homogenization and $0.5 \mathrm{~min}$. in the ice.

L-carnitine analysis

Total free L-carnitine in the yeast biomass was determined using an L-Carnitine Assay Kit according to the assay procedure (Abnova, Catalog № KA0860). 
Statistical analysis of data

All data are expressed as a mean \pm SD (standard deviation) of three independent experiments. The differences between the concentrations of L-carnitine in the biomasses of $Y$. lipolytica strains growing at the different conditions were compared to Y. lipolytica ATCC A-101 cultured in the YPD medium at the temperature of $30^{\circ} \mathrm{C}$ and $\mathrm{pH} 6.0$ with two-sided student's $t$-test, using Statistica software version 12.0. The $P$ value $<0.05$ was considered statistically significant.

\section{Declarations}

\section{Acknowledgements}

The authors wish to thank team of Wrocław University of Environmental and Life Sciences for isolation of Y. lipolytica A-101 strain.

\section{Authors contributions}

MEJ and AM designed the experiments; MJ and KK performed experimental research; MEJ and AM performed data analysis. MEJ wrote the manuscript text; MEJ, KK, ES and AM edited the manuscript text. $\mathrm{KK}, \mathrm{ES}$ and $\mathrm{AM}$ critically revised the manuscript. All authors read and approved the final manuscript.

\section{Competing interests}

The authors declare no competing interests.

\section{Data availability}

The datasets generated for this study are available on request to the corresponding author.

\section{Ethics declarations}

Not applicable

\section{Consent for publication}

Not applicable

\section{Funding}

This work was supported by the European Regional Development Fund under the Innovative Economy Operational Programme 2007-2013 [UDA-POIG-01.04.00-24-132/11-00].

\section{References}


1. Meadows, J. A. \& Wargo, M. J. Carnitine in bacterial physiology and metabolism. Microbiol. 161, 1161-1174 (2015).

2. Stephens, F. B., Constantin-Teodosiu, D. \& Greenhaff, P. L. New insights concerning the role of carnitine in the regulation of fuel metabolism in skeleton muscle.. J. Physiol. 581, 431-444 (2007).

3. Strijbis, K. et al. Identification and characterization of a complete carnitine biosynthesis pathway in Candida albicans. FASEB J. 23, 2349-2359 (2009).

4. Swiegers, J. H., Dippenaar, N., Pretorius, I. S. \& Bauer, F. F. Carnitine-dependent metabolic activities in Saccharomyces cerevisiae: three carnitine acetyltransferases are essential in a carnitine-dependent strain. Yeast. 18, 585-595 (2001).

5. Flanagan, J.L., Simmons, P.A., Vehige, J., Willcox, M.D. \& Garrett, Q. Role of carnitine in disease.Nutr Metab. 16, 30, 10.1186/1743-7075-7-30 (2010).

6. van Rossum, H. M. et al. Requirements for carnitine shuttle-mediated translocation of mitochondrial acetyl moieties to the yeast cytosol. mBiol. 7 (16), 10.1128/mBio.00520 - 16 e00520 (2016).

7. Franken, J., Burger, A., Swiegers, J. H. \& Bauer, F. F. Reconstruction of the carnitine biosynthesis pathway from Neurospora crassa in the yeast Saccharomyces cerevisiae. Appl. Microbiol. Biotechnol. 99, 6377-6389 (2015).

8. Krivoruchko, A., Zhang, Y., Siewers, V., Chen, Y. \& Nielsen, J. Microbial acetyl-CoA metabolism and metabolic engineering.Metab Eng.28, 28-42, 10.1016/j.ymben.2014.11.009 (2015).

9. Chen, L., Zhang, J. \& Chen, W. N. Engineering the Saccharomyces cerevisiae $\beta$-oxidation pathway to increase medium chain fatty acid production as potential biofuel. Plos One. 9, e84853 https://doi.org/10.1371/journal.pone.0084853 (2014).

10. Mlickova, K. et al. Lipid Accumulation, Lipid Body Formation, and Acyl Coenzyme A Oxidases of the Yeast Yarrowia lipolytica.Appl. Environ. Microbiol.70,3918-3924(2004).

11. Wang, H.J. et al. Evaluation of acyl coenzyme A oxidase (Aox) isozyme function in the n-alkaneassimilating yeast Yarrowia lipolytica.J Bacteriol. 181, 5140-5148, (1999).

12. Dulermo, R., Gamboa-Melendez, H., Ledesma-Amaro, R., Thevenieau, F. \& Nicaud, J-M. Unraveling fatty acid transport and activation mechanisms in Yarrowia lipolytica. Biochim. Biophys. Acta. 1851, 1202-1217 https://doi.org/10.1016/j.bbalip.2015.04.004 (2015).

13. Dellomonaco, C., Rivera, C., Campbell, P. \& Gonzalez, R. Engineered respire-fermentative metabolism for the production of biofuels and biochemical from fatty acid-rich feedstock. Appl. Environ.

Microbiol. 76, 5067-5078 (2010).

14. Haddouche, R. et al. Roles of multiple acyl-CoA oxidases in the routing of carbon flow towards $\beta$ oxidation and polyhydroxyalkanoate biosynthesis in Yarrowia lipolytica.FEMS Yeast. Res.10, 917927 (2010).

15. Ledesma-Amaro, R. \& Nicaud, J-M. Yarrowia lipolytica as a biotechnological chassis to produce usual and unusual fatty acids. Prog. Lipid. Res. 61, 40-50 https://doi.org/10.1016/j.plipres.2015.12.001 (2016). 
16. Bellou, S. et al. Microbial oils as food additives: recent approaches for improving microbial oil production and its polyunsaturated fatty acid content. Curr. Opin. Biotechnol. 37, 24-35 (2016).

17. Carsanba, E., Papanikolaou, S. \& Erten, H. Production of oils and fats by oleaginous microorganisms with an emphasis given to the potential of the nonconventional yeast Yarrowia lipolytica. Crit. Rev. Biotechnol. 38, 1230-1243 (2018).

18. Jach, M. E. et al. Yarrowia lipolytica grown on biofuel waste as a source of single cell protein and essential amino acids for human diet. Saudi. J. Med. Pharm. Sci. 3, 1344-1351 (2017).

19. Jach, M. E., Masłyk, M., Juda, M., Sajnaga, E. \& Malm, A. Vitamin B12-enriched Yarrowia lipolytica biomass obtained from biofuel waste. Waste. Biomass. Valori. 11, 1711-1716 https://doi.org/10.1007/s12649-018-0521-5 (2020a).

20. Jach, M. E. \& Serefko, A. Nutritional yeast biomass: characterization and application. In Diet, Microbiome and Health. Handbook of food bioengineering. (ed. Grumezescu, A. \& Holban, AM..) 237-270(Academic Press, Elsevier, 2018).

21. Lopes, M., Gomes, A. S., Silva, C. M. \& Bel, I. Microbial lipids and added value metabolites production by Yarrowia lipolytica from pork lard. J. Biotechnol. 265, 76-85 (2018).

22. Papanikolaou, S. \& Aggelis, G. Yarrowia lipolytica: A model microorganism used for the production of tailor-made lipids. Eur. J. Lipid. Sci. Technol. 112, 639-654 https://doi.org/10.1002/ejlt.200900197 (2010).

23. Jach, M. E. et al. Production of enriched in B vitamins biomass of Yarrowia lipolytica grown in biofuel waste. Saudi. J. Biol. Sci. https://doi.org/10.1016/j.sjbs.2021.02.027 (2021).

24. Katre, G., Joshi, C., Khot, M., Zinjarde, S. \& RaviKumar, A. Evaluation of single cell oil (SCO) from a tropical marine yeast Yarrowia lipolytica NCIM 3589 as a potential feedstock for biodiesel. AMB Express. 2, https://doi.org/10.1186/2191-0855-2-36 (2012).

25. Saygün, A., Sahin-Yesilcubuk, N. \& Aran, N. Effects of different oil sources and residues on biomass and metabolite production by Yarrowia lipolytica YB 423 - 12. J. Am. Oil. Chem. Soc. 91, 1521-1530 (2014).

26. Vasiliadou, I. et al. Biomodification of fats and oils and scenarios of adding value on renewable fatty materials through microbial fermentations: modelling and trials with Yarrowia lipolytica. J. Clean. Prod. 200, 1111-1129 (2018).

27. Tzirita, M., Papanikolaou, S., Chatzifragkou, A. \& Quilty, B. Waste fat biodegradation and biomodification by Yarrowia lipolytica and a bacterial consortium composed of Bacillus spp. and Pseudomonas putida. Eng. Life. Sci. 18, 932-942(2018).

28. Somba, M. K. et al. Production of single cell protein (SCP) and essentials amino acids from Candida utilis FMJ12 by solid state fermentation using mango waste supplemented with nitrogen sources. Afr. J. Biotechnol. 17, 716-723 (2018).

29. EFSA. Safety of Yarrowia lipolytica yeast biomass as a novel food pursuant to Regulation (EU) 2015/2283. 10.2903/j.efsa.2019.5594 (2015). 
30. Groenewald, M. et al. Yarrowia lipolytica: Safety assessment of an oleaginous yeast with a great industrial potential. Crit. Rev. Microbiol.40,187-206.

31. Xu, P., Qiao, K., Ahn, W. S. \& Stephanopoulos, G. Engineering Yarrowia lipolytica as a platform for synthesis of drop-in transportation fuels and oleochemicals. PNAS. 113, 10848-10853 (2016).

32. Jach, M. E. et al. Statistical evaluation of growth parameters in biofuel waste as a culture medium for improved production of single cell protein and amino acids by Yarrowia lipolytica. AMB Expr. 10, https://doi.org/10.1186/s13568-020-00968-x (2020b).

33. Papanikolaou, S., ·Chevalot, I., 'Komaitis, M., Marc, I. \& Aggelis, G. Single cell oil production by Yarrowia lipolytica growing on an industrial derivative of animal fat in batch cultures. Appl. Microbiol. Biotechnol. 58, 308-312 https://doi.org/10.1007/s00253-001-0897-0 (2002).

34. Papanikolaou, S., Muniglia, L., Chevalot, I., Aggelis, G. \& Marc, I. Accumulation of a Cocoa-Butter-Like Lipid by Yarrowia lipolytica Cultivated on Agro-Industrial Residues. Curr. Microbiol. 46, 124-130 (2003).

35. Zhao, M. X., Chi, Z., Chi, Z. M. \& Madzak, C. The simultaneous production of single-cell protein and a recombinant antibacterial peptide by expression of an antibacterial peptide gene in Yarrowia lipolytica. Proc. Biochem. 48, 212-217(2016).

36. Lopes, M., Gomes, A. S., Silva, C. M. \& Belo, I. Microbial lipids and added value metabolites production by Yarrowia lipolytica from pork lard. J. Biotechnol. 265, 76-85 (2018).

37. Lopes, M., Miranda, S. M., Alves, J. M., Pereira, A. S. \& Belo, I. Waste Cooking Oils as Feedstock for Lipase and Lipid-Rich Biomass Production. Eur. J. Lipid. Sci. Technol. 121, 1800188, 101002/ejlt.201800188(2019).

38. Papanikolaou, S., Chevalot, I., Komaitis, M., Aggelis, G. \& Marc, I. Kinetic profile of the cellular lipid composition in an oleaginous Yarrowia lipolytica capable of producing a cocoa-butter substitute from industrial fats. Antonie van Leeuwenhoek. 80, 215-224 (2001).

39. Daskalaki, A., Perdikouli, N., Aggeli, D. \& Aggelis, G. Laboratory evolution strategies for improving lipid accumulation in Yarrowia lipolytica. Appl. Microbiol. Biotechnol. 103, 8585-8596 (2019).

40. Dourou, M., Aggeli, D., Papanikolaou, S. \& Aggelis, G. Critical steps in carbon metabolism affecting lipid accumulation and their regulation in oleaginous microorganisms. Appl. Microbiol. Biotechnol. 102, 2509-2523 (2018).

41. Dominguez, A., Deive, F. J., Angeles Sanroman, M. \& Longo, M. A. Biodegradation and utilization of waste cooking oil by Yarrowia lipolytica CECT 1240. Eur. J. Lipid. Sci. Technol. 112, 1200-1208 (2010).

42. Saper, R. B., Eisenberg, D. M. \& Philips, R. S. Common dietary supplements for weight loss. Am. Farm. Physician. 70, 1731-1738 (2004).

43. Zhang, Q. et al. The effect of maternal chromium status on lipid metabolism in female elderly mice offspring and involved molecular mechanism. Biosci. Rep. 28 (2), BSR20160362 https://doi.org/10.1042/BSR20160362 (2017). 
44. Vlatka, G. Z., Vesna, S. T., Sloboda, G., Lavoslav, L. \& Damir, K. Chromium uptake by Saccharomyces cerevisiae and isolation of glucose tolerance factor from yeast biomass. J. Biosci. 26, 217-223 (2001).

\section{Figures}

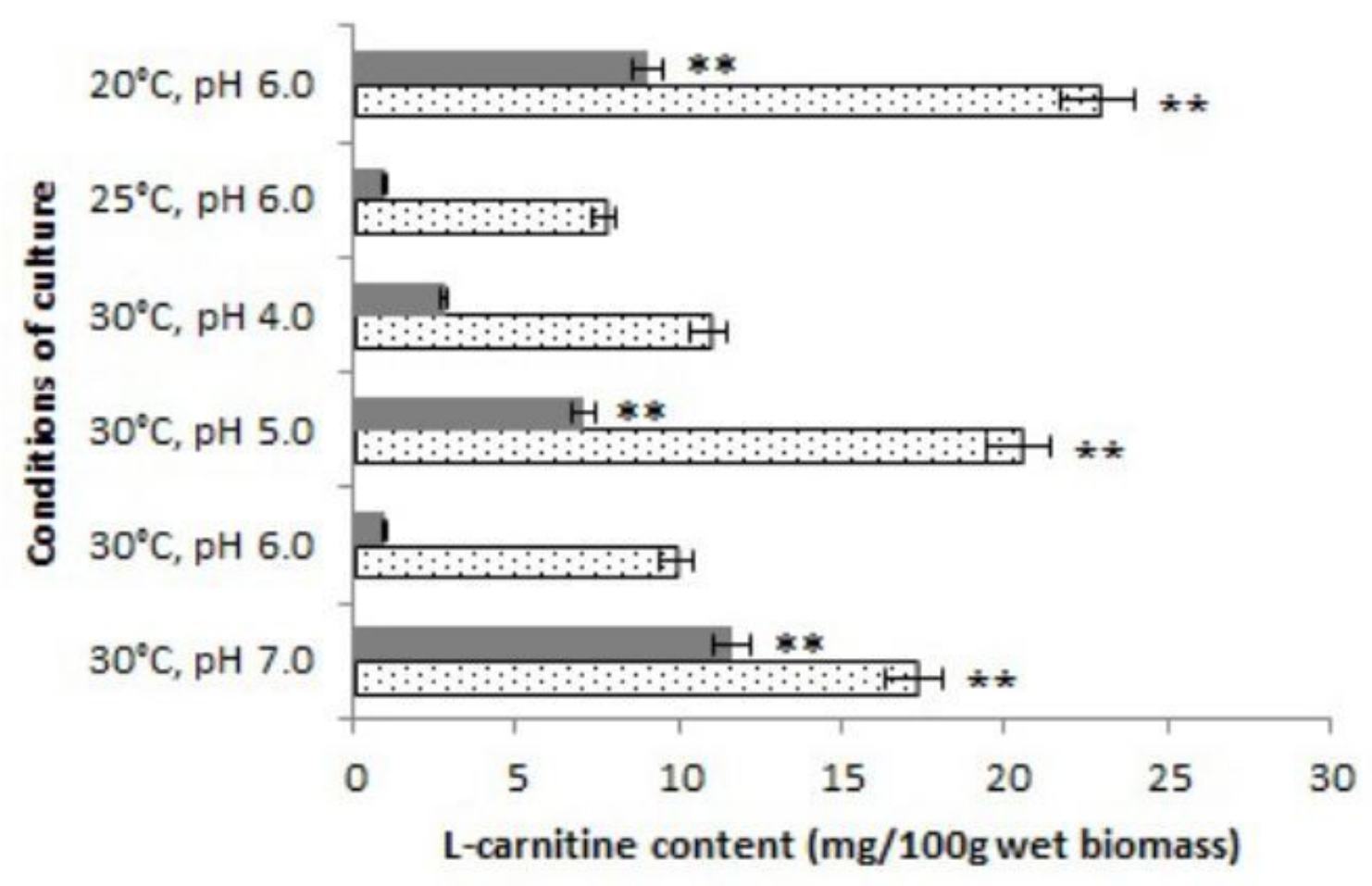

\section{Figure 1}

Total free L-carnitine concentration in wet biomass of Y. lipolytica strains cultured in the YPD medium at different conditions. Y. lipolytica ATCC 9793 (dotted squares); Y. lipolytica A-101 (filled squares). **P<0.01 indicate significant difference compared to reference cultivation. 

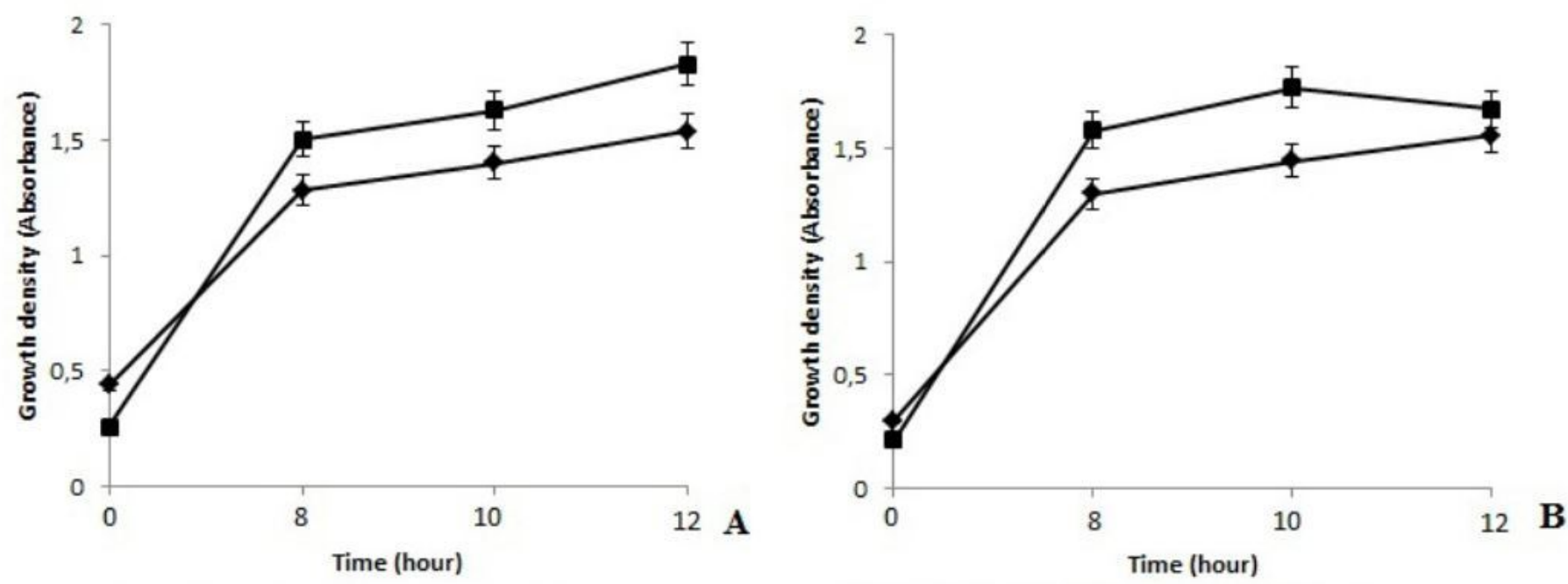

\section{Figure 2}

Growth density of Y. lipolytica. A. Y. lipolytica ATCC 9793; B. Y. lipolytica A-101 cultured in SK medium (biofuel waste), $\left(\mathrm{pH} 6.0,30^{\circ} \mathrm{C}\right)$ unsupplemented or supplemented with iron(II) sulfate $(0.01 \mathrm{mg} / \mathrm{L})$, trimethyllysine hydrochloride $(0.1 \mathrm{~g} / \mathrm{L})$ and $\mathrm{L}$-ascorbic acid $(0.002 \mathrm{~g} / \mathrm{L})$. 